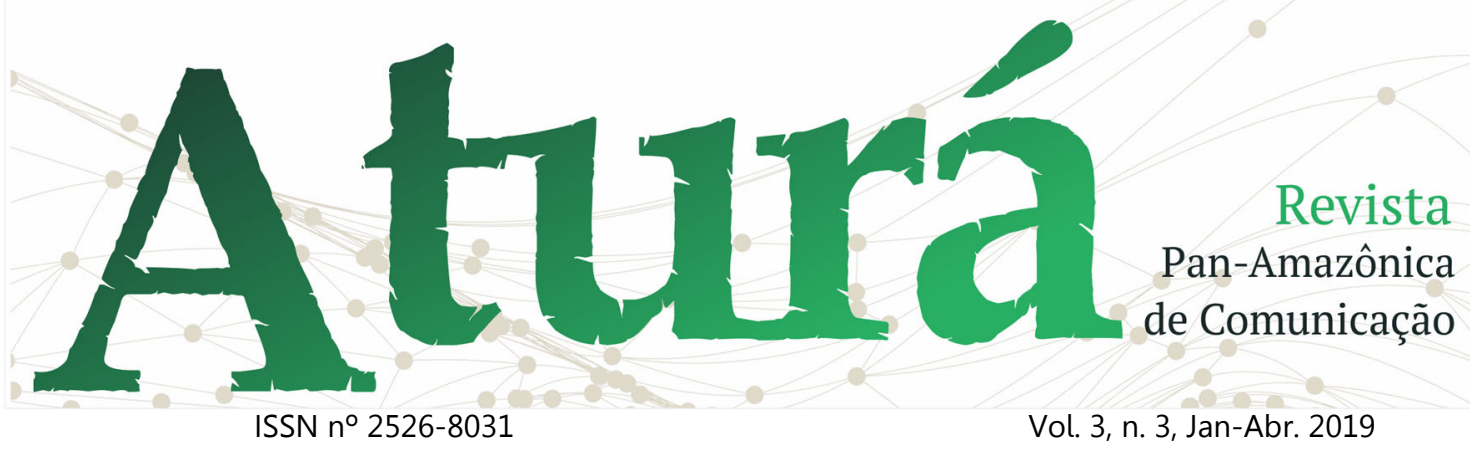

\title{
PESQUISA EM COMUNICAÇÃO NA AMAZÔNIA
}

Em sua primeira edição de 2019, a revista Aturá traz um dossiê sobre a Pesquisa em Comunicação na Amazônia. É um tema de extrema importância, que procura não apenas abordar questões comunicacionais em interface com as especificidades e temas próprios da região, mas, sobretudo, contribuir para a compreensão da complexidade que cerca o fazer da pesquisa em comunicação nessa região. E para isso, nada melhor do que trazer uma mostra das pesquisas em si.

Ao todo, esta edição reúne doze artigos decorrentes do esforço contínuo de doutores, doutorandos, mestres, mestrandos, graduados e graduandos envolvidos em iniciação científica. Esses trabalhos foram selecionados dentre cerca de 50 artigos apresentados no II Encontro de Pesquisa em Comunicação na Amazônia (EPCA), promovido pelo Programa de Pós-Graduação Comunicação, Cultura e Amazônia (PPGCOM) da Universidade Federal do Pará (UFPA) e que nasceu da iniciativa dos mestrandos do Programa. Em 2018, esse evento, que nomeia este dossiê da Aturá, contou também com a parceria do Programa de PósGraduação em Comunicação, Linguagens e Cultura (PPGCLC) da Universidade da Amazônia (UNAMA).

É importante ressaltar que em apenas duas edições, O EPCA já mostrou a sua maturidade e delineou o seu perfil, propondo-se a ser um palco para discutir também a Pan-Amazônia. O lançamento de sua Jornada de Internacionalização, com a presença de pesquisadores da Pontifícia Universidad Javeriana de Bogotá, da Colômbia, reforçou esse delineamento, convidando-nos para conhecer um 


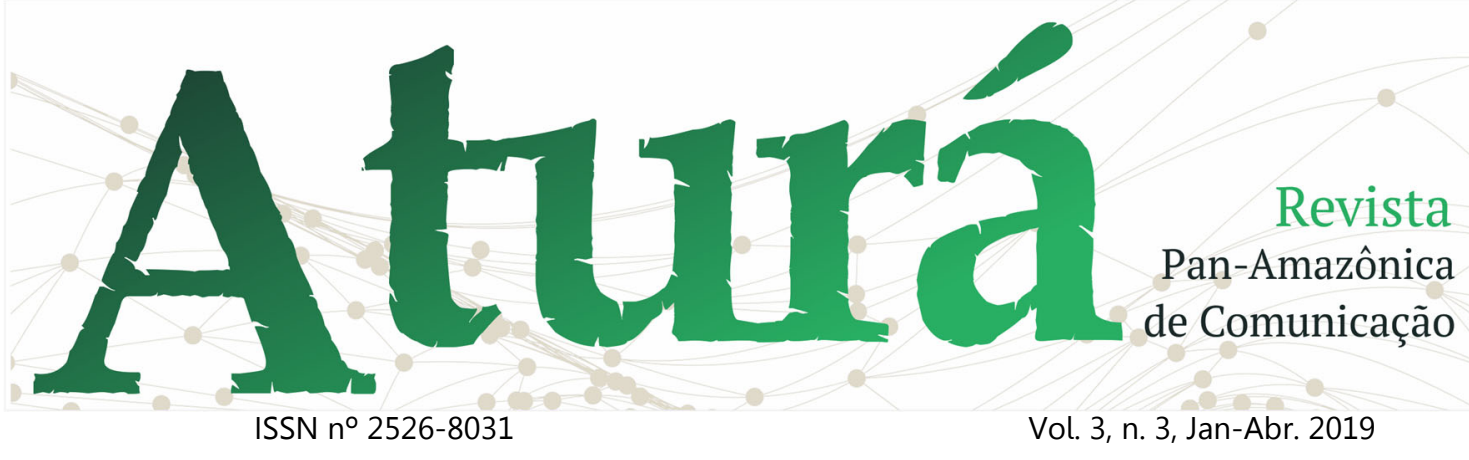

pouco mais sobre as temáticas, problematizações, divergências e confluências que despontam nos cenários pan-amazônicos da Comunicação.

De seus Grupos de Trabalho, vieram os textos publicados nesta edição da Aturá. Do GT Comunicação e Socialidades, o artigo Surrealidade cotidiana: a teatralização do imaginário amazônico nos espetáculos dos grupos de Cordão de Pássaros, dos pesquisadores Otacílio Amaral Filho, Bianca Conde Leão e Laís Teixeira da Silva Pelaes enfocam a comunicação, nessa tradicional manifestação da cultura popular da Amazônia, usando os conceitos de espetáculo (Requena, 1988) e de imaginário amazônico (Paes Loureiro, 1995). Já Elielton Benedito Castro Gomes, autor do trabalho Pelas margens da cidade: lazer e sociabilidade no espaço urbano belenense nos anos de 1950, dá ênfase às experiências festivas realizadas em espaços de lazer e sociabilidade do subúrbio da amazônica Belém do Pará.

Do GT Comunicação e Política, no artigo Deliberação e Comunicação: aproximações conceituais para atuação em escolas, as pesquisadoras Suzana Magalhães e Danila Cal buscam compreender como o processo comunicativo contribui para a realização das capacitações em deliberação nas escolas públicas. Já o artigo Mobilizações pré-eleições presidenciais 2018 no Pará: grupos e eventos relacionados à \#EleNão no Facebook, as autoras Brenda Rachit e Maíra Evangelista de Sousa propõem uma reflexão sobre como as novas formas de mobilização com base online, aliadas às questões de gênero e representatividade eleitoral, contribuem para a construção de comunidades instantâneas de práticas transformadoras que se consolidam no espaço físico.

Já no GT Comunicação, Gênero e Sexualidades Plurais, as pesquisadoras Luciana Miranda Costa e Raissa Lennon Sousa partem de uma charge publicada no jornal australiano Herald Sun para analisar a construção da imagem da mulher negra na mídia. Essa reflexão ampara-se em aspectos dos estudos de 


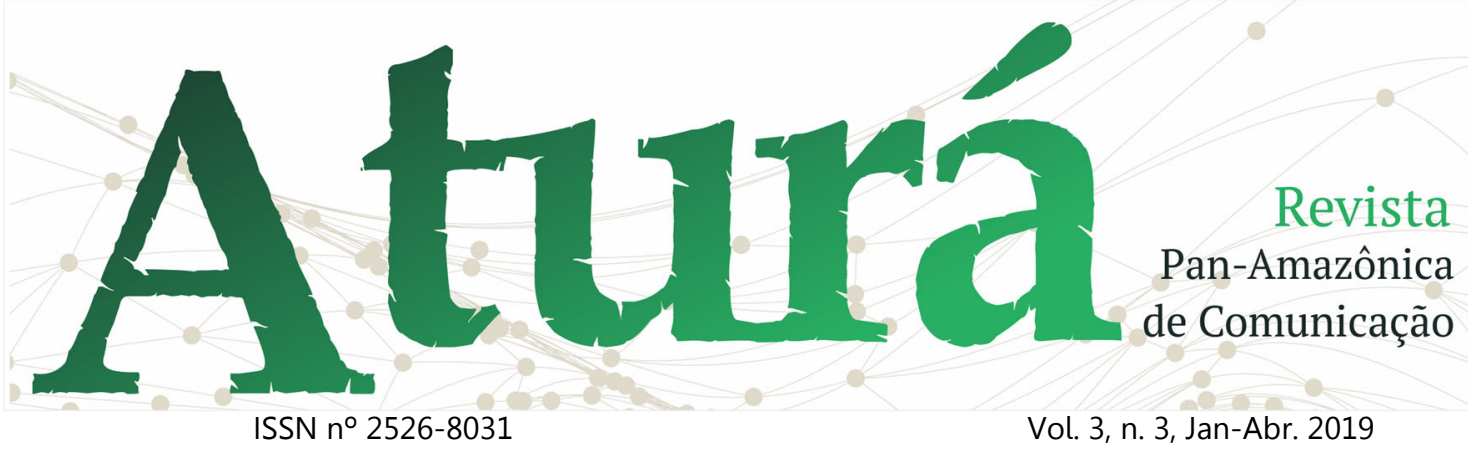

comunicação, gênero e questões raciais e resulta no artigo $O$ outro do outro: Serena Williams e a construção da imagem da mulher negra na mídia.

A mulher negra na imprensa também foi abordada no artigo Jornalismo $e$ negritude: a representatividade da mulher negra na veiculação do jornal O Liberal, de Alice de Fátima Nogueira de Moura e Ingrid Pereira Reis, as quais alertaram para a quase inexistência de espaço dado aos conteúdos protagonizados por negras na imprensa e o consequente reforço do silenciamento dessas mulheres.

Já no GT Comunicação e Imagem, a autora Mariana Almeida, no artigo Drogadição, sofrimento e telenovela: dimensões de estilo em Vale Tudo e em Verdades Secretas, propõe um ensaio sobre os modos de construção estilística do sofrimento associado às experiências de drogadição de duas personagens de telenovelas brasileiras. E no trabalho De quem...é...o próximo...ex": comunicação, imagem e performance no reality show De Férias com o Ex - Brasil, os autores Erick Matheus Nery e Manuela do Corral Vieira debatem sobre padrões de beleza e de comportamento, verificando como a construção de estereótipos sociais passa pelo discurso midiático.

No GT Comunicação e Narrativas do Contemporâneo, Pedro Loureiro de Bragança trata Os agentes das narrativas nas reportagens da Agência Pública de Reportagem e Jornalismo Investigativo acerca dos Projetos Hidrelétricos do Tapajós utilizando a abordagem metodológica do campo social, de Bourdieu, associada à análise da narrativa, de Luiz Gonzaga Mota. Já os autores Renata da Cruz Paes, Priscila Sanjuan Medeiros e Altem Nascimento Pontes, no artigo Jornais The Guardian, El País e O Globo: o que apresentam sobre os povos indígenas de Belo Monte, enfocam a construção do personagem indígena na imprensa internacional e nacional.

Dentro desse GT, pela primeira vez no EPCA, houve uma Sessão Transmídia. Dentre os trabalhos apresentados aqui, o artigo Vigilância nas redes 


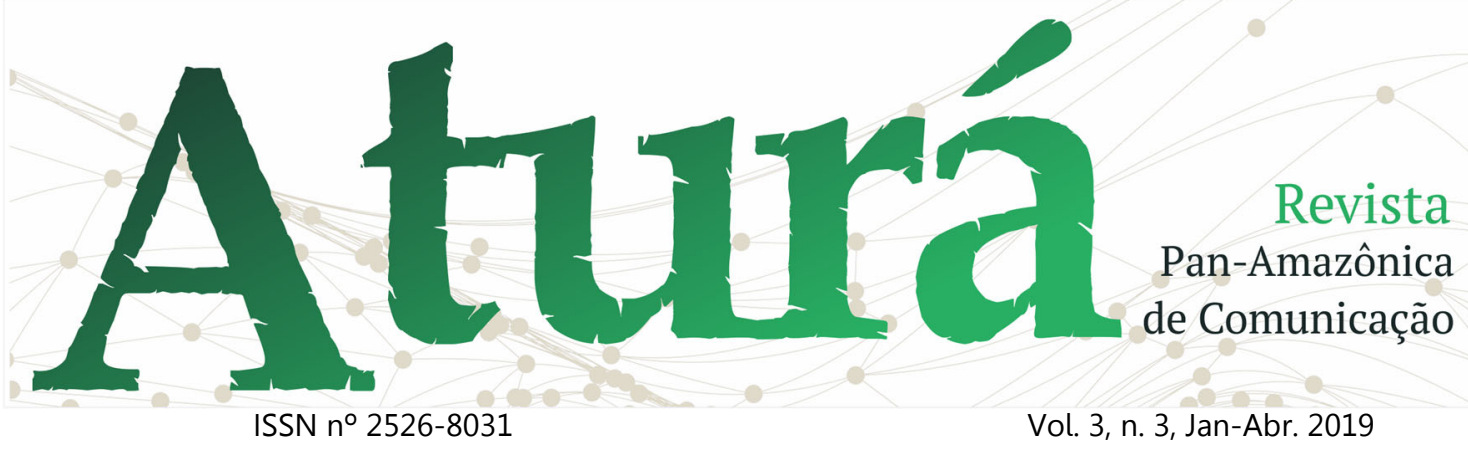

digitais: um estudo do caso de James Gunn, dos autores André Carvalho, Krisllen Mayra Coelho, Leonardo Ramon Carneiro, Sarah Maria Rocha e Rosaly Brito, ampara-se nos estudos de Fernanda Bruno (2013) e Paula Sibilia (2018) para analisar as práticas de vigilância e monitoramento que ocorrem no ambiente virtual. Esse trabalho procura evidenciar o impacto que essas práticas podem gerar na vida das pessoas e compreender que, nas redes digitais, os usuários podem ser vítimas e/ou juízes do conteúdo exposto em seus perfis. Já o texto Características da transmídia no jornalismo: regularidades em produtos multiplataforma, dos pesquisadores Wellington Rafael da Rocha e Elaide Martins, traz o resultado de um mapeamento das características da narrativa transmídia identificadas no jornalismo desenvolvido por grupos de comunicação no Norte do Brasil. O artigo também enfoca o jornalismo no âmbito nacional e internacional e aponta suas reconfigurações e as características transmídia que se apresentam com maior regularidade.

Assim, com esse conjunto de artigos, o primeiro dossiê temático da AturáRevista Pan-Amazônica de Comunicação publicado neste ano, torna-se especial, pois reúne os trabalhos mais expressivos do II EPCA, realizado em Belém durante o período de 21 a 23 de novembro de 2018. Um dossiê que dá início ao ciclo de edições previstas para 2019.

Na seção TEMAS LIVRES, o artigo MIDIATIZAÇÃO E RELIGIÃO: utilização de estratégias midiáticas pela paróquia São João Batista (Presidente Médici-

Rondônia), de Sandro Adalberto Colferai e Cadidja Medeiros Barros da Cunha, tem como foco compreender o processo de utilização de estratégias midiáticas pela Paróquia de Presidente Médici, formada no contexto da colonização agrícola do estado de Rondônia, a fim de identificar a sua relação com as escolhas midiáticas adotadas. A utilização do conceito Midiatização (SANTI, 2016) trabalhado por Martino (2016) em relação à religião, das práticas midiáticas 


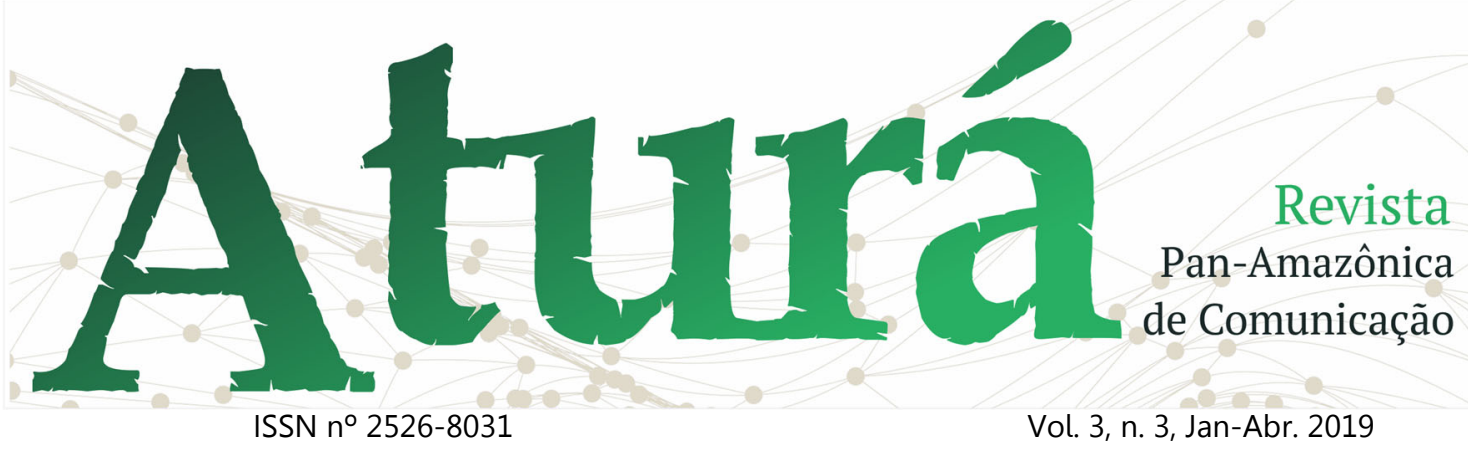

adotadas pela Paróquia, tem como objetivo explicar a relação entre a comunidade católica e as novas configurações sociais ocasionadas pela colonização do estado.

No artigo FRONTISPíCIOS: a negação da legitimidade simbólica das esferas do Palácio Araguaia na construção do imaginário cultural do Tocantins, Ana Carolina Costa dos Anjos, Cleide das Graças Veloso dos Santos, apresentam uma análise narrativa de 13 notícias de acesso livre, localizadas na mídia online do Tocantins, que tratam do período entre dois momentos polêmicos da trajetória dos frontispícios do Palácio Araguaia: a retirada e localização dos fragmentos da obra artística. A amostra, objeto da análise, foi obtida por meio de consultas na plataforma de pesquisa Google e dos respectivos sites, com combinações dos termos utilizados como unidades de referência. Sob o método de Análise de Conteúdo, esta pesquisa tem o objetivo de verificar evidências da utilização de estratégias representacionais na construção da memória e imaginário cultural, bem como da negação da apropriação simbólica na identidade cultural do Estado, e promover uma reflexão a partir da performance do assunto na cobertura jornalística.

No artigo A VOLTA DO GATO PRETO: a narrativa de viagem como jornalismo literário na obra do Dr. Erico Verissimo, Eduardo Ritter, apresenta os elementos que permitem considerar o relato de viagem $A$ volta do gato preto como uma narrativa que se enquadra no gênero Jornalismo Literário na categoria de livro-reportagem-viagem, proposta por Lima (2004). Para tanto, identificaramse cinco temáticas principais que aparecem no enredo desse texto misto: viagem, família, universidade, cultura e guerra.

E, finalizando nosso número, o artigo A TV PÚBLICA NO BRASIL E PORTUGAL: Aspectos conceituais e históricos, de Gizeli Costa Bertollo Menezes; Francisco Gilson Rebouças Porto Junior; Yuri Vinicius Silva, José Lopes da Cruz Filho e Kécia Garcia Ferreira, onde tentam compreender melhor o sistema público 


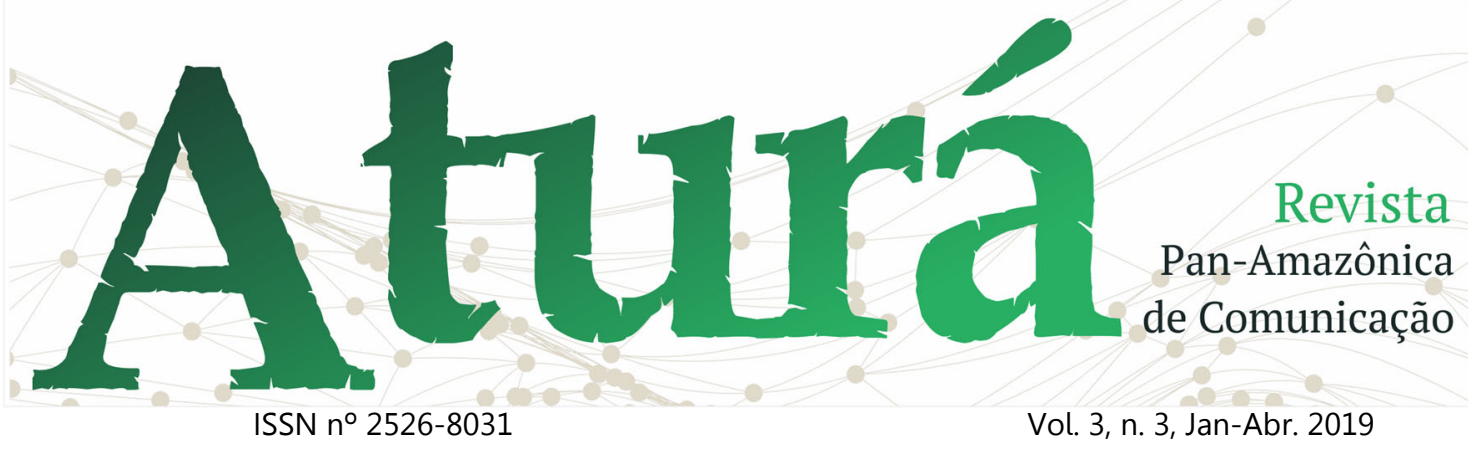

de televisão em Portugal e no Brasil, especificamente as emissoras RTP1 e TV Brasil. Embora os dois países sejam marcados por fortes ligações históricas, culturais e linguísticas, se distanciam no que diz respeito a radiodifusão pública. Enquanto em Portugal a televisão já nasce sob o domínio estatal, que posteriormente vai se moldando aos princípios do serviço público, no Brasil chega pelas mãos da iniciativa privada, que por quase duas décadas dominou de forma exclusiva o cenário televisivo, imprimindo seu modelo no país.

Desejamos uma excelente e proveitosa leitura!!!

Belém - PA, Boa Vista - RR, Palmas - TO, Vilhena - RO, Janeiro de 2019.

Editor convidado/ Guest Editor/ Editor invitado

Elaide Martins - Universidade Federal do Pará (UFPA), Brasil.

Editores Gerais / Chief Editor / Editor general

Francisco Gilson Rebouças Porto Junior - Universidade Federal do Tocantins

(UFT), Brasil.

Sandro Colferai - Universidade Federal de Rondônia (UNIR), Brasil. Vilso Junior Santi - Universidade Federal de Roraima (UFRR), Brasil. 